\title{
Trace element composition of South China Sea oceanic crust
}

\author{
ANTONIO J. LUNA ${ }^{1}$, JEFFREY G. RYAN ${ }^{1}$ \\ XIAO-LONG HUANG ${ }^{2}$
}

${ }^{1}$ School of Geosciences, University of South Florida, Tampa, FL 33620; aluna2@mail.usf.edu, ryan@usf.edu

${ }^{2}$ Guangzhou Institute of Geochemistry, Chinese Academy of Sciences ; xlhuang@gig.ac.cn

The compositions of lavas in volcanic arcs reflect contributions from both downgoing slab and mantle wedge sources. The likely significance of slab-derived source contributors may be constrained through characterizing the elemental compositions of those materials that reach trenches, for comparisons to arc volcanic outputs. While the roles of marine sediments and oceanic crust in subduction recycling have been characterized at a global scale for the major ocean basins $[1,2,3,4]$, however, finer scale subduction recycling studies have largely not been done. The South China Sea (SCS) is a marginal marine basin within which subduction of local ocean crust and sediments occurs only at the Manila trench feeding the Luzon volcanic arc. International Ocean Discovery Program Expeditions (Exp.) 349, 367 and 368 to the SCS recovered basement at six locations (U1431, U1433, U1434, U1500, U1502 and U1504). We have analyzed representative unaltered and altered basaltic rock samples from the SCS sites to develop a compositional profile for the ocean crust across the basin.

Rare earth element and mobile element systematics of basement samples from Exp. 367 and 368 (U1500 \& U1502) indicate extensively altered basalt relative to fresher samples recovered during Exp. 349 (Sites U1431, U1433, U1434). Hole U1500 samples show elevated contents of mobile species $(\mathrm{Rb}, \mathrm{Cs}, \mathrm{K})$ and evidence for $\mathrm{Ce}$ anomalies, with normalized REE abundance patterns similar to U1434. Hole U1502 basalts are highly altered, with evidence for redistribution of less-mobile species ( $\mathrm{Zn}, \mathrm{Sr})$. Schistose mafic rocks from Hole U1504 show distinctively enriched LREE patterns relative to all other Holes, and show prominent enrichments in mobile elements and key immobile species (Th). The compositional variations among recovered SCS mafic rocks place constraints on the materials subducted along strike at the Manila trench, suggesting possible and significant variations in the down-going plate contributions to Luzon arc lavas.

[1] Plank \& Langmuir, Nature, 1993; [2] Plank \& Langmuir, Chem Geol. 1998; [3] Plank, Treatise on Geochemistry (2014); [4] Kelley et al. GCubed, 2003. 